\title{
SUCESSÃO DE ESTADO NO DIREITO INTERNACIONAL PÓS-MODERNO ${ }^{1}$
}

\author{
STATE SUCCESSION IN POST-MODERN INTERNATIONAL LAW
}

Paulo Borba Casella ${ }^{2}$

pour Isabelle Pingel, en souvenir heureux

\begin{abstract}
Resumo:
Sucessão de Estado, mais que um simples capítulo na história do Direito Internacional, como ocorrida no passado teve sucessivas reavaliações, após a descolonização (1945-1960) e depois, novamente, nos anos 90, na Europa; a matéria continua um tema além das obrigações bilaterais, incluindo tratamento multilateral de questões fundamentais para o sistema internacional como um todo; o tema permanece atualizado e não deve ser negligenciado, como parte de um esforço para assegurar o papel do Direito Internacional no mundo de hoje.

Palavras-chave: Direito Internacional. Sucessão de Estado. Enfoque histórico e evolução da matéria no Direito Internacional. Bilateralidade e multilateralidade de tratados e de obrigações internacionais. Papel das organizações internacionais na regulação da sucessão de Estados. Perspectivas de evolução do tratamento do tema.
\end{abstract}

\begin{abstract}
:
State-succession, more than simply a chapter in the history of International Law, as occurred in the past has had successive reappraisals, after decolonization (19451960) and therafter again in the 1990's in Europe; the matter remains as an issue beyond bilateral obligations and approaches, to include multilateral treatment of core issues for the international system, as a whole; the matter remains updated and should not be neglected, as part of an effort to ensure the role of International Law in today's world.
\end{abstract}

Keywords: International Law. State-succession. Historical focus and evolution of the discipline in the International Law. Bilateriality and multilateriality of international treatys and obligations. Role of international organizations in the state-succession regulation. Prospects of the theme's treatment evolution.

Aristóteles, na Política, primeiro questiona a questão da identidade do Estado, quando há mudança da tirania, para a oligarquia, no sentido de se determinar em que momento se está lidando com pessoa determinada, ou com o Estado. Essa questão, da

\footnotetext{
1 Prova de erudição, realizada em $1^{\circ}$ de junho de 2007, no concurso para titularidade em Direito Internacional Público, na Faculdade de Direito da Universidade de São Paulo.

2 Professor Titular do Departamento de Direito Internacional da Faculdade de Direito da Universidade de São Paulo.
} 
identidade e da continuidade do Estado - o mesmo tema, que já abordava Aristóteles, se põe em relação à questão da sucessão de Estado até o atual momento pós-moderno. Nesta matéria muito se fala a respeito da diversidade. A diversidade é apontada pela prática dos Estados, a diversidade é apontada pela doutrina, mas, justamente, seria importante buscar a unidade, em meio a essa diversidade : em que medida existe linha comum, que pode ser apresentada, em relação à questão da sucessão de Estados, e, justamente, no mesmo sentido, de evolução do conjunto do Direito Internacional, a matéria da sucessão de Estados se põe como a passagem da bilateralidade para a multilateralidade, do acordo pontual para o quadro institucional de uma coesão que se procura aumentar, e também da busca de racionalidade. Em lugar de enfatizar a diversidade caberia, justamente, tentar ver essas grandes linhas do conceito e da evolução da sucessão de Estados, e, nesse sentido, se pode considerar a perspectiva histórica, e a base de direito positivo, onde caberia subdividir a perspectiva histórica e a base conceitual - com destaque para as Convenções de Viena, de 1978 e 1983. Em seguida, a construção da sucessão de Estado, nas fontes acessórias do Direito Internacional, com o papel da jurisprudência internacional e da doutrina. Em terceiro lugar, caberá considerar o enfoque conceitual da multilateralidade: nas Convenções multilaterais gerais, nas Convenções multilaterais restritas, e, em conclusão, se poderá chegar ao teste da sucessão de Estado, à luz do Direito Internacional presente.

Na perspectiva histórica, há momento, entre o final do séc. XVIII e início do séc. XIX, com a independência dos Estados Unidos da América, e a independência, no início do séc. XIX, das antigas colônias da Espanha e de Portugal, nas Américas. Ocorre, aí, dicotomia, que se põe, nesse contexto, e que permanece, até hoje: é unilateral ou é bilateral a sucessão de Estado? Há dado de consenso ou há dado de ruptura? Essa mesma questão, pode ser ilustrada, por exemplo, contrapondo o Tratado Jay, de 1791, entre a Inglaterra e EUA, e toda a negociação que leva ao Tratado de Lisboa, de 1825, pelo qual se completa o processo de independência do Brasil e o reconhecimento da condição deste, enquanto sujeito de Direito Internacional.

Entre as soluções unilaterais de ruptura e as soluções de consenso, ou soluções negociadas, o exemplo brasileiro, com as particularidades da nossa história, mostra, justamente, a construção da sucessão de Estado, onde até há o detalhe da indenização pela Biblioteca Real portuguesa, incluído nessa conta entre o Brasil e Portugal, com a mediação da Inglaterra, da qual resulta o núcleo original da Biblioteca Nacional, do Rio de Janeiro.

Nessa perspectiva histórica, três grandes momentos podem ser apontados, no curso do século XX: o primeiro, logo após a Primeira Guerra Mundial, com o fim 
do Império russo, o fim do Império otomano, o fim do Império áustro-húngaro - e quando se coloca a tentativa de "redesenhar" o mapa da Europa, passando dos Impérios multinacionais, para o conceito de Europa das nacionalidades. Nesse momento, a idéia de se atribuir a condição de Estado a cada Nação: cada Nação, um Estado e, a cada Estado, deveria corresponder uma Nação. Isso corresponde a uma série de mudanças de conceitos e de operacionalidade, também em matéria de Direito Internacional. A sucessão de Estado, nesse momento, se pôs, em relação a várias questões, que permanecem presentes e atuais. A tentativa feita pela União Soviética, no sentido de renegar as dívidas do regime anterior, do período dos czares, em razão da ruptura, que descaracterizaria a continuidade, leva a situação de isolamento internacional, durante alguns anos, até que seja, depois, transigida essa recusa inicial, de modo a chegar a uma solução negociada. Esse exemplo é relevante, para mostrar, justamente, como a ruptura, sem negociação, em confrontação direta e aberta das regras do Direito Internacional, então vigentes, pode perdurar, durante algum tempo, mas acaba, depois, por impor-se a realidade da norma internacional, que levou a ver resgatada tal condição. O mesmo vai aparecer, algumas décadas depois, com relação às conseqüências da descolonização, após a Segunda Guerra Mundial.

$\mathrm{Na}$ construção de uma nova Europa, com vários casos de sucessão de Estado, se teve momento e contexto, no final da Primeira Guerra Mundial. Ao final da Segunda Guerra Mundial, aparece o segundo grande momento da sucessão de Estados, no século XX: entre 1945 e 1960 cerca de uma centena de novos Estados aparecem, e todos esses Estados, progressivamente, são acolhidos, como sujeitos de Direito Internacional, e admitidos na condição de membros da Organização das Nações Unidas.

A ampliação do número de Estados, no contexto internacional, fazse de modo concomitante ao do papel de Organização, que tente organizar esse novo e substancialmente diverso contexto internacional, de modo colegiado. A questão do estabelecimento do Estado, com o reconhecimento e a sucessão, negociada ou-não, que passa da bilateralidade estrita, do passado, para, mais e mais, a um contexto de multilateralidade, institucionalizada e negociada.

No processo de descolonização duas correntes puseram-se, com muita clareza, e confrontação, em relação à base dos conceitos. De um lado, a idéia da tabula rasa ou clean slate, como diz a doutrina de língua inglesa, onde se recusaria todo e qualquer vínculo, assumido pela antiga metrópole, e não teriam qualquer impacto ou relevância, em relação ao novo sujeito de Direito Internacional. No extremo oposto, a pretensão da sucessão universal: o novo sujeito de Direito Internacional estaria obrigado a 
dar prosseguimento a todos os vínculos, que, antes, tenham sido acordados pela metrópole, no grande número de situações antes coloniais.

Qual é a lição a ser extraída do período de descolonização, que se estende de 1945 a 1960 ? É, justamente, que nenhuma das duas posições extremas pode prevalecer. A posição intermediária, de sucessão modulada, prevaleceu em grande número de casos, em que, apesar de declaração inicial, dos novos Estados, e do surgimento da idéia de categoria nova do Direito Internacional, na qual se inscreveriam os Estados recém-independentes, a lição da história mostra, mais uma vez, que, apesar da diversidade, há consistência das regras, e uma certa linha geral, na administração e na construção do Direito Internacional, se fez muito clara. Vários casos foram objeto, por exemplo, nas antigas colônias inglesas, o ato de independência da então chamada Burma, atual Birmânia, o ato de independência da Indonésia em relação aos Países-Baixos, bem como das Filipinas, em relação aos EUA, marcados por tentativas de acordo, e alguns percalços, na implementação, na prática.

$\mathrm{O}$ único caso de transição, sem qualquer vínculo programado de Direito Internacional, foi a independência do Congo, porque o tratado, entre o Congo e a Bélgica, de 1960, nunca chegou a entrar em vigor. Não por acaso, terá sido essa, justamente, transição das mais complexas e problemáticas, do período, com efeitos prolongados.

No caso das antigas colônias francesas, a Constituição da República francesa, de 1958, cria a idéia de comunidade, que teria a Presidência da França e numa certa medida, o exercício da condição de sujeito de Direito Internacional ainda permaneceria, em boa medida, com a metrópole, que se tornava uma espécie de primus inter pares. Essa idéia, nunca foi totalmente implementada, mas se põe nessa mesma linha, de sucessão negociada.

Curiosamente, depois do fim do período da descolonização, se poderia crer ter terminado a sua carreira, esse tema, da sucessão de Estado. Quando foram negociadas as Convenções de Viena, de 1978, sobre "sucessão de Estados em matéria de tratados”, e a Convenção, de 1983, sobre a "sucessão de Estados em matéria de bens, arquivos e dívidas de Estado", a impressão, que se teve, durante a negociação, e o pouco impacto que estas convenções alcançaram, refletiria a percepção da época, quanto a tratar-se de tema velho, de tema, do qual não mais se teria necessidade. Curiosamente aparece aí essa nouvelle vague em matéria de sucessão de Estado, no Direito Internacional. Nos anos 90, 26 novos Estados ingressam na ONU, o último dos quais Montenegro, no ano de 2006: isso nos vem mostrar que esse tema, longe de ser página da História do Direito Internacional, continua presente, e ainda suscita questões, as mais variadas. Nessa nova corrente de sucessão de Estado, curiosamente, vemos alguns processos de aglutinação, como a unificação da 
Alemanha, a unificação do Iêmen, mas, sobretudo, três divisões, que mostram ser cada caso um caso, e terem particularidades no seu tratamento e nas suas conseqüências para os Estados, diretamente interessados, como para o conjunto da comunidade internacional.

A divisão entre a República Tcheca e a Eslováquia - que põe termo à existência da Tchecoslováquia, como sujeito de Direito Internacional, quando ingressam as duas novas repúblicas, como integrantes da ONU, em janeiro de 1993 e, depois, em maio de 2004 como dois dos novos integrantes da União Européia. Alguns Autores dizem que a Tchecoslováquia seria o exemplo de "divórcio perfeito": foi planejado segundo o Direito, houve estrita proporcionalidade, na divisão de dívidas e patrimônio, na mesma proporção da população, ou seja: 2/3 para a República Tcheca, 1/3 para a Eslováquia.

No caso da URSS, várias situações se colocam em relação a essa sucessão de Estados. A Federação russa foi aceita como a sucessora, na maioria das organizações internacionais, inclusive por questão de conveniência, para o conjunto dos Estados, e em vista da necessidade de estabilidade, de todo o sistema internacional - a Federação Russa conserva, inclusive, o assento permanente no Conselho de Segurança da ONU, o poder de veto, no seio deste, e a sua condição de potência nuclear. Ao lado da Rússia, das outras integrantes da antiga União das Repúblicas Socialistas Soviéticas, os três bálticos, a Estônia, Letônia e a Lituânia, apresentam-se empenhados em resgatar a sua soberania, do ponto em que tinha sido interrompida, por invasão feita pela URSS, em 1940.

A violação do Direito Internacional cometida meio século antes teria sido elemento legitimador da construção desse reconhecimento, com a ficção de ser retomada a vida independente desses três Estados. Não seriam, assim, novos Estados, mas tratar-seia de resgatar a condição soberana, daqueles três Estados que, temporariamente, embora por lapso de 50 anos, tinham cessado a sua condição de exercer a condição de sujeitos de Direito Internacional. Enquanto a Federação russa sucede a URSS, na maioria das organizações, os três bálticos se colocam como "agora podemos voltar a exprimir a nossa opinião depois de ter ficado privados de voz no cenário internacional", e as demais Repúblicas tiveram transição interessante, porquanto a Ucrânia e Belarus já tinham, se não a realidade, ao menos a ficção de membros originários da ONU, o que lhes permitiu resgatar essa condição, e continuar, inclusive, como membros da ONU, sem apresentarem novas candidaturas. Mas, em relação às demais Repúblicas, fez-se o modelo de transição, da Comunidade de Estados Independentes (CEI), o que já contém certa contradição, na sua denominação, visto ser, ao mesmo tempo, "comunidade" e composta de "Estados independentes", com as duas Atas, de Alma Ata e de Minsk, de 1991, por meio das quais 
se cria quadro jurídico transitório, para regular a sucessão, entre o fim da URSS, e o atual quadro instaurado.

Em matéria de tratados, várias questões foram resolvidas mas, sobretudo, em matéria nuclear, que era e permanece questão vital, para a sobrevivência da humanidade, houve consistência na interpretação, e na aplicação do Direito Internacional, que merece ser levada em conta.

O Tratado de não-proliferação nuclear (TNP), de 1968, o Tratado dos mísseis antibalísticos (ABM), de 1972, com o seu Protocolo, de 1974, e o Memorandum de Entendimento, de 1997, mostram, exatamente, prevalecer o interesse do conjunto dos Estados, em linha condutora onde, apesar da multiplicidade de casos, houve consistência na interpretação e na aplicação. Houve "desnuclearização" do Cazaquistão, da Ucrânia e da Belarus, e a correspondente transferência da condição de parte contratante nos Tratados nucleares, para a Federação russa, sucedendo a URSS.

O caso da URSS mostra várias hipóteses possíveis de sucessão de Estado, desde a continuidade no caso da Rússia, o resgate de identidade que tinha sido interrompida por ato de força em relação à Estônia, Letônia e Lituânia, o resgate de situação fictícia, que depois se torna realidade, com a Ucrânia e a Belarus, e a construção empírica de modelo, em relação às demais Repúblicas que, por meio de acordos informais, preparam o caminho para a independência e a convivência organizada, entre as antigas Repúblicas componentes da URSS e os demais Estados, no sistema internacional.

Tchecoslováquia e URSS foram bons exemplos dessa nouvelle vague em matéria de sucessão de Estado, desde os anos 90 até a década atual. Temos, ao lado destes, exemplo penoso do esfacelamento da antiga República Socialista Federativa da Iugoslávia, que se traduziu em sucessivas levas de guerra civil, envolvendo a Eslovênia, a Croácia, a Bósnia-Herzegóvina, até Kosovo, ainda em 1999.

Curiosamente, a independência de Montenegro, em 2006, marca o fim, e o último ato da divisão da Iugoslávia, mas este se faz por meio de referendum e vai à população festejar, nas ruas, depois de ser o resultado anunciado, passear com bandeiras do novo Estado, que se criou, de forma pacífica e controlada. Quanto sangue se derramou entre 1991 e 2006. Vimos ressurgir na antiga Federação iugoslava a incidência dos mais graves crimes, tipificados pelo Direito Internacional: genocídio, crimes contra a humanidade, crimes de guerra e de agressão. Limpeza étnica e matança de milhares de civis voltaram às manchetes da Imprensa mundial.

Antes que Montenegro obtivesse sua independência pacífica, e se desse a sucessão de Estado, que se reflete já em caso, julgado, em fevereiro de 2007, pela Corte 
Internacional de Justiça (CIJ), é, justamente, nesse momento, que se põe a necessidade de olhar, para o que foi cometido, em matéria de crimes contra a humanidade, violação de direitos fundamentais, genocídio, limpeza étnica e a barbárie que acreditávamos ter afastado do planeta que volta a acontecer na antiga Iugoslávia.

Isso leva a criação interessante: nos anos 90, o Conselho de Segurança da ONU, interpretando a sua prerrogativa de zelar pela proteção da paz e da segurança internacionais, no sentido do capítulo VII da Carta da ONU, determina a criação de dois Tribunais Penais Internacionais ad hoc para investigar e punir os crimes, tipificados pelo Direito Internacional, praticados na antiga Iugoslávia e em Ruanda. Não se questione o mérito da intenção de coibir tais violações da norma internacional, embora sem base legal específica. É, assim, relevante atentar para essa dimensão, justamente, no sentido da construção de jurisdição internacional, propriamente dita, para coibir crimes de guerra e crimes contra a humanidade. A diferença principal desses dois Tribunais Penais Internacionais ad hoc, do início dos anos 90 - e isso antes que viesse o Estatuto de Roma, de 1998, criar o Tribunal Penal Internacional, efetivado em 2002 - esses dois Tribunais Penais Internacionais de Ruanda e da Iugoslávia são mais internacionais e têm uma mais adequada fundamentação jurídica do que acontecera ao final da Segunda Guerra Mundial, com os Tribunais de Nuremberg, em 1945, e de Tóquio, em 1946.

Essa perspectiva histórica, apresentada não como fim em si mesma, mas para mostrar, justamente, que o tema da sucessão de Estado não se faz em abstrato e, ao mesmo tempo, a contemplação dos casos concretos não deve absorver excessivamente a atenção, a ponto de obscurecer a percepção das grandes linhas de evolução e de tratamento do tema.

As duas Convenções, de 1978 e de 1983, em matéria de sucessão de Estado, foram feitas para consolidar base de Direito Internacional positivo, ao lado dessa perspectiva histórica. Enquanto base de Direito Internacional codificado, a "Convenção das Nações Unidas sobre sucessão de Estados em matéria de tratados", de 1978, somente, em 1996, alcança o número suficiente de ratificações para a sua entrada em vigor. Por ironia do destino, serão, justamente, os novos países da Europa Central, aqueles que compõem o número necessário, para chegar às 15 (quinze) ratificações, estipuladas como condição para a entrada em vigor da Convenção de 1978. Por sua vez, a Convenção de 1983, ou a "Convenção das Nações Unidas sobre a sucessão de Estados em matéria de bens, arquivos e dividas de Estado", concluída em 1983, tem, até hoje, somente 7 (sete), do mínimo de 15 (quinze), ratificações necessárias, para a sua entrada em vigor. Não está em vigor e provavelmente não virá tão cedo a entrar. 
Estas duas Convenções, não se pode dizer que tenham alcançado grande relevância prática. Na decisão da CIJ, em 1997, no caso Gabcikovo-Nagymaros, a Corte entendeu que o art. 12 da Convenção, de 1978, reflete a existência de norma geral de Direito Internacional, e esta norma estaria simplesmente espelhada na Convenção - a Convenção não a teria criado, simplesmente teria exprimido, mediante instrumento codificado, a existência de Direito Internacional consuetudinário. Mas, além da possível aplicação dessas duas Convenções, enquanto instrumentos de Direito Positivo, é importante atentar, justamente, para a condição da escolha política, feita pela comunidade internacional, através dos representantes na Comissão de Direito Internacional (CDI) da ONU, no sentido, primeiro, de terem escolhido codificar essa matéria e, em segundo lugar, o modo como o fizeram. Assim, em lugar de deixar agir simplesmente o costume, houve a escolha política, de codificar essas questões, ao mesmo tempo em que o resultado da codificação não alcança acolhida tão calorosa. Este é paradoxo a se levar em conta, quanto ao fato de que o trabalho de codificação, desenvolvido desde o final da Segunda Guerra Mundial, conta grandes realizações: algumas convenções, resultantes do trabalho da CDI, tornaramse sinônimo do Direito Internacional vigente, e praticamente não são objeto de discussão, tais como, paradigmaticamente, a Convenção de Viena sobre relações diplomáticas, de 1961, a Convenção de Viena sobre relações consulares, de 1963, a Convenção de Viena sobre Direito dos tratados, de 1969, não exatamente na mesma medida, no caso da Convenção sobre missões especiais, de 1975 e, ainda uma vez, na Convenção de Viena sobre direito dos tratados entre organizações internacionais e Estados ou entre organizações internacionais, de 1986. Esses são marcos bem-sucedidos da codificação do Direito Internacional, além e ao lado de toda a codificação do Direito do espaço extraatmosférico, que acontece no curso dos trinta anos seguintes ao final da Segunda Guerra Mundial, entre 1945 e 1975. Pouco, ou nada, se fez em matéria de codificação, do Direito Internacional espacial, desde então.

Ao mesmo tempo a Convenção das Nações Unidas sobre o Direito do Mar, de 1982, pelo número de Estados, pela abrangência do tema, e pela criação de sistema de solução de controvérsias específico - o Tribunal Internacional para Direito do Mar, sediado em Hamburgo - traz marco de consolidação de todo este ramo do Direito Internacional, e se conta dentre as grandes realizações, em matéria de codificação e de consolidação de institutos, de normas e de procedimentos internacionais.

Nessa mesma linha, se se pretender avaliar, a codificação da sucessão de Estados não teve impacto eqüivalente, enquanto codificação: teve impacto, simplesmente, enquanto reflexo do costume, e este é o tratamento que lhe confere a CIJ, no caso de 1997, 
quando na discussão a respeito do Projeto Gabcikovo-Nagymaros, entre a Eslováquia e a Hungria. Ao responder à invocação da Eslováquia, quanto a serem normas de Direito Internacional cogente os arts. 12 e 34 da Convenção de Viena sobre sucessão de Estados em matéria de tratados, de 1978, não se manifesta a Corte a respeito do art. 34, mas declara ser o art. 12 parte do Direito Internacional geral, e, portanto, seria vinculante, e deveria ser aplicado o seu conteúdo. Justamente colocou-se o foco do caso na questão de sucessão de Estados, entre o final da antiga Tchecoslováquia, e a condição da Eslováquia, como Estado sucessor, ao mesmo tempo em que a discussão se punha com relação às conseqüências ambientais da implementação do projeto, e a determinação da extensão das obrigações, entre a Hungria e a Eslováquia, tal como as decide a Corte, em 1997.

Esse quadro convencional serve como escolha política, como indicação de critérios, mas não representou grande realização, enquanto obra de codificação do Direito Internacional. Por isso, é preciso, na passagem para o segundo tópico, considerar as fontes acessórias do Direito Internacional, na construção da regulamentação da sucessão de Estados: o papel da jurisprudência e o papel da doutrina, inclusive do Institut de Droit International.

$\mathrm{Na}$ jurisprudência internacional há questão interessante, que já se coloca, entre a CPJI e a CIJ: não se pode deixar de considerar o caráter de sucessão, embora não se possa falar em identidade, mas claramente existe continuidade de atuação, entre ambas, não-só no aspecto físico, mas sobretudo no aspecto imaterial, do legado da jurisprudência, emanada da Corte Permanente, e mantido pela Corte Internacional de Justiça, ao qual esta se reporta sistematicamente.

A Corte Permanente tinha o Estatuto de Jurisdição autônoma, enquanto a CIJ é o principal órgão judiciário das Nações Unidas, como diz a própria Carta. De tal modo, mesmo no tocante à sua condição jurídica, há diferença entre ambas. Mas ocorre continuidade, que caracterizaria talvez a sucessão entre estes dois tribunais internacionais. A Corte Permanente, em algumas ocasiões, enfrentou questões de sucessão de Estados. No Caso dos Faróis, julgado em 1934, tratava-se da sucessão de concessões para a manutenção de faróis, feitas ainda ao tempo do Império otomano, a sociedade francesa, prestadora de serviços de manutenção desses faróis. Depois do final da Primeira Guerra Mundial, quando do fim do Império otomano, algumas dessas ilhas foram transferidas à soberania da Grécia. A Grécia, como Estado sucessor, entendia não estar vinculada, àquelas concessões, feitas pelo Estado predecessor. A Corte amplia a sua interpretação e declara que sim, aqueles contratos eram válidos e deveriam ser mantidos em vigor. Nessa decisão, de 1934, a matéria de sucessão de Estado foi foco do caso. 
De forma semelhante, no Caso da Estrada de Ferro Panevezys-Saldutiskis, de 1939, também se tratava de questão de sucessão, em matéria de contratos celebrados ainda na época do Império dos czares, que depois nessa discussão entre a Lituânia e a Polônia, foi preciso que a Corte estabelecesse em que limite deveria ser observada a continuidade.

Vários casos são examinados pela CIJ. Em um deles, no Caso do Templo de Préah Vihéar, de 1961, entre o Camboja e a Tailândia, a Corte reforça o entendimento da Corte Permanente, no sentido de afirmar a necessidade de que os tratados, em matéria de delimitação de fronteiras, sejam mantidos, como marcos relevantes, não-só enquanto instrumentos vinculantes, entre as partes, como para o conjunto dos Estados que compõem o sistema internacional. Neste caso, havia a sucessão entre o Protetorado francês, depois o Camboja, e a alegação de que esses tratados teriam perecido, com o fim do período colonial. A Corte determina seu entendimento, no sentido de que estes representavam a expressão não-só da vontade das partes, e a vontade internacional do Camboja expressa à época pela metrópole francesa, mas, sobretudo, que em matéria de fronteiras, deve ser observado e deve prevalecer o interesse do conjunto dos Estados, em ter o mínimo transtorno possível, em caso de sucessão de Estados.

Isso vai caracterizar jurisprudência, sistematicamente orientada nesse mesmo sentido, em matéria de fronteiras, como característica da sucessão automática. Também aparece a questão da sucessão automática, em matéria de sucessão de fronteiras, no caso de fronteiras, entre Burkina Faso e Mali, julgado em 1986; também, no caso das fronteiras marítimas, terrestres e insulares, entre El Salvador e Honduras, com intervenção da Nicarágua; mais uma vez, no Caso do Projeto Gabcikovo-Nagymaros, de 1997, entre a Hungria e a Eslováquia, em que se caracterizou, mais de uma vez, a obrigação de manter a condição do Estado predecessor, que tivesse validamente contraído a obrigação em relação ao outro Estado contratante.

Ao lado da sucessão automática em matéria de fronteiras, coloca-se a nãosucessão em matéria de tratados políticos, tratados de aliança militar, de neutralidade, de assistência recíproca, pois estes, normalmente, perecem ou desaparecem, quando há uma mudança de Estado.

Entre a sucessão automática, em matéria de fronteiras, e a não-sucessão em matéria de tratados políticos, temos conjunto de situações de sucessão modulada, e essa justamente permite ver a evolução da bilateralidade, para a institucionalização da multilateralidade, no Direito Internacional pós-moderno. 
Antes de passar para essa perspectiva, vejamos a doutrina, como coloca o tema da sucessão de Estados. Esse enfoque da doutrina começa no final do séc. XIX, e por razões óbvias são Autores italianos e alemães que, em razão da condição dos seus respectivos Estados, após a unificação da Alemanha e da Itália, em 1870, procuram responder a essa questão: em que medida haveria a sucessão de Estados, em que medida haveria identidade, em que medida poderia haver continuidade. Essa doutrina, do final do séc. XIX, ainda com Cavaglieri e outros, permanece como referência válida no Direito Internacional a respeito do tema.

Há, na década de 20, ênfase na doutrina com Sack e Feichenfeld, que se exprime na preocupação com relação à transferência de dívida de Estado, e isso como conseqüência e efeito da moratória e da denegação da assunção de obrigação de débito do antigo regime dos czares, pela então recém-instaurada URSS.

Nas décadas de 30 e 40, a ênfase passa, com Kelsen e outros, para a ênfase sobre a sucessão, em matéria de tratados. Como deveria se dar, e em que medida e extensão, a sucessão em relação aos tratados?

Após a Segunda Guerra Mundial, há toda uma leva de Autores que se debruçam sobre o tema, e vão enfocar a sucessão de Estados, sob a perspectiva da descolonização. Alguns afirmam que a tabula rasa deveria ser o critério de base e o Estado recém-independente, como nova entidade de Direito Internacional, deveria reger-se por normas próprias. Nesse mesmo sentido, Mohamed Bedjaoui, em 1970, ${ }^{3}$ Yilma Makonnen, da Etiópia, em $1986^{4}$ - tanto um quanto outro em cursos na Haia - e contrariamente a esses, Daniel o'Connell, da Austrália, também em 1970, na Haia, ${ }^{5}$ enfatiza a necessidade da continuidade, da identidade e do interesse coletivo dos Estados, em ter o mínimo possível de controvérsias, em relação a esse quadro da descolonização.

Nos anos 90, surge toda uma nova fase de literatura a respeito do tema da sucessão, com focos, muitas vezes, claramente voltados para a questão da antiga Iugoslávia, da URSS e a Tchecoslováquia, pela forma pacífica e juridicamente adequada como foi conduzida, suscita literatura mais amena, e menos sujeita a se tornar objeto de controvérsias.

3 BEDJAOUI, Mohammed. Problèmes récents de succession d'états dans les états nouveaux. Recueil des Cours de L'Academie de Droit International, Leiden, v. 130, p. 454-585, 1970.

4 MAKONNEN, Yilma. State succession in Africa: selected problems. Recueil des Cours de L'Academie de Droit International, Leiden, v. 200, p. 93-234, 1986.

O'CONNELL, Daniel Patrick. Recent problems of state succession in relation to new states. Recueil des Cours de L'Academie de Droit International, Leiden, v. 130, p. 95-206, 1970. 
Há todo um conjunto de Autores, que abordam o tema, nos anos 90, com destaque para todo o curso de Brigitte Stern, em 1996, na Haia, quase 500 páginas ${ }^{6}$, analisando como diz logo no início, somente "alguns dos aspectos" desse complexo tema.

Vários colóquios foram feitos, para organizar enfoques, sobre a identidade, a continuidade, a ruptura, a extinção da personalidade internacional, envolvendo vários casos, de diversos países. O exemplo, de um lado, da unificação da Alemanha e do Iêmen, o exemplo de outro lado, da divisão pacífica da Tchecoslováquia, sangrenta da Iugoslávia, e com várias soluções intermediárias, o Caso da URSS, ao lado de outras tantas. Volta o tema a ser candente, como escolha para os colóquios, para os artigos de revista, e para a discussão em obras recentemente publicadas.

Este é o papel da jurisprudência e da doutrina, enquanto fontes acessórias do Direito Internacional. E foram contribuições relevantes, para o tratamento e a compreensão do tema.

A perspectiva histórica nos dá alguns dados; a perspectiva da base de direito codificado nos dá alguns princípios, e essas duas fontes acessórias, a jurisprudência e a doutrina, vêm completar o quadro, e nos permitem passar para o terceiro item, e o dado mais interessante, justamente a instauração da multilateralidade e a sucessão nas organizações internacionais de vocação universal, e em relação aos tratados multilaterais.

Esse grupo de enfoque conceitual mostra, justamente, que apesar de tanto ser visto, na doutrina antiga, haver tal diversidade, ao ponto desta impedir a caracterização de grandes regras e tendências, como Manlio Udina, na Haia, em 1933, ${ }^{7}$ ou Erik Castrén, da Finlândia, em 1951, na Haia, ${ }^{8}$ há consistência, e esta, justamente, é construída pela norma internacional; a continuidade da norma, em situações de descontinuidade, política e histórica.

Essa multilateralização do tratamento legal do tema da sucessão de Estados, inclusive, em algumas situações, põe a observância de normas e de princípios de Direito Internacional como condição para o ingresso na ONU, constituem manifestação de vontade coletiva, de interesse de conjunto, e nos permite acreditar, em alguns momentos, que se

\footnotetext{
STERN, Brigitte. La succession d'états. Recueil des Cours de L'Academie de Droit International, Leiden, v. 262, p. 9-438, 1996.

7 UDINA, Manlio. La succession des états quant aux obligations internationals autres que les dettes publiques Recueil des Cours de L'Academie de Droit International, Leiden, v. 44, p. 665-773, 1933.

8 CASTRÉN, Erik J. Aspects récents de la succession d'états. Recueil des Cours de L'Academie de Droit International, Leiden, v. 78, p. 379-506, 1951.
} 
pode passar daquele direito de mútua abstenção e de coexistência, ao patamar de Direito Internacional de cooperação, como proporia o modelo da Carta da ONU.

A multilateralização, concomitantemente à criação de regime coordenado de implantação têm alguns destaques, que justificam a menção, dada a sua importância. Ter-se conseguido construir a sucessão nuclear, de forma pacífica e planejada, é realização importante, que deve ser levada em conta: o tratado de não proliferação nuclear, o tratado dos mísseis antibalísticos, como já referi. Esse conjunto de regras, em matéria da sucessão nuclear, é realização não-só técnica, mas realização importante para a sobrevivência da humanidade no planeta, como adverte Christian Tomuschat no seu curso geral, na Haia, em 1999: o Direito Internacional como condição para a sobrevivência da humanidade. ${ }^{9}$

Em matéria de sucessão nuclear isso não é só expressão marcante, é realidade que foi controlada, e poderia ter riscos maiores. Que, ademais, continuam presentes. E precisam ser administrados, pelo sistema internacional.

Ao lado dessa situação multilateral, há quadros regionais específicos em que, também, se constrói sucessão planejada. A Convenção do Danúbio, assinada em Belgrado, em 1948, no seu Protocolo adicional, de 1998, põe, justamente, essa transição, com alteração de algumas das partes contratantes, e a criação da categoria de Estado interessado, embora não diretamente vinculado a fronteiras, ao longo do Rio Danúbio. Esse quadro regional, de navegação do Rio Danúbio, com a Convenção de 1948, adaptada em 1998, seria exemplo de sucessão planejada e regulada pelo Direito Internacional.

Há desenvolvimento relevante, no contexto europeu, em que a Convenção de Estrasburgo, de 1997, sobre nacionalidade, tinha somente alguns princípios gerais, mas não continha normas precisas, com relação à nacionalidade, no caso de sucessão de Estados. Essa Convenção, de 1997, é completada pela Convenção do Conselho da Europa, sobre prevenção de apatridia, no caso de sucessão de Estados, assinada em Estrasburgo, em 2006.

Esta Convenção européia, de 2006, faz menção à Convenção de 1997, e no considerando seguinte menciona ser, ainda hoje, a sucessão de Estados, uma dentre as causas principais da situação de apatridia, e essas situações têm de ser coibidas e limitadas. Essa Convenção do Conselho da Europa, do ano de 2006, mostra quanto o tema continua presente e a sua regulação pelo Direito Internacional continua necessária.

9 TOMUSCHAT, Christian. International law: ensuring the survival of mankind in the eve of a new century: general course on public international law. Recueil des Cours de L'Academie de Droit International, Leiden, v. 281, p. 9-438, 1999 . 
A lição que se pode tirar desse conjunto da sucessão de Estados é exatamente, como dizia no início, no sentido de que, além da diversidade aparente, dessa diversidade da prática, dessa diversidade do enfoque dos Autores, o mais interessante e relevante será, justamente, apontar a linha-mestra, e esta se coaduna com o Direito Internacional.

O Direito Internacional pode demonstrar certa flexibilidade, na feitura das normas, na aplicação dessas mesmas normas, mas tem ao mesmo tempo uma consistência de base, que se conservou, como dado positivo, para se ter presente. Nesse sentido deve o tema ser avaliado.

Há também a questão de materialidade dessa norma. O reconhecimento progressivo de normas cogentes, inclusive em relação a direitos políticos dos Estados, seria desenvolvimento impensável, há 50 anos, e foi várias vezes afirmado pela Corte Internacional de Justiça. Apesar de elemento de vontade do Estado, há interesse maior da Coletividade, enquanto conjunto, que interessa a todos os Estados do planeta. E essa construção se põe, tanto do ponto de vista do conteúdo, quanto do ponto de vista da operacionalidade: a coordenação, no âmbito das organizações internacionais leva à sucessão planejada, em alguns casos. Não podemos esquecer a tragédia da antiga Iugoslávia, visto termos, novamente, há pouco tempo, acontecerem crimes contra a humanidade, e a prática de genocídio. Foi, justamente, caso de aplicação da Convenção para a prevenção e a repressão do crime de genocídio, assinada em Nova York, em 1948, o objeto do Caso entre a Bósnia-Herzegóvina e a então ainda existente República da Iugoslávia, que reunia Sérvia e Montenegro. A Corte prolata medidas cautelares, em 1996, e julga o mérito em fevereiro de 2007.

Entre as medidas cautelares, em 1996, e o julgamento de mérito, em fevereiro de 2007, se dá a independência de Montenegro, e a Corte reconhece que deveria ser permitido ao Montenegro retirar-se do processo, porquanto a discussão dizia respeito à Sérvia e, portanto, não teria razão para se obrigar o Montenegro a permanecer no caso.

Nessa decisão, a CIJ faz menção a valores compartilhados, a necessidades comuns, à dimensão maior, que deve ser levada em conta, além do interesse, contratualmente estipulado, dos Estados.

Para encerrar essa questão, poder-se-ia justamente apontar ser a sucessão de Estado a ilustração de desenvolvimento conceitual, e das bases do Direito Internacional, que evolui da bilateralidade pontual, para a institucionalização da multilateralidade. Evolui do interesse político, onde cada Estado seria soberano, para a caracterização de valores, que devem ser preservados, pelo conjunto de Estados, ainda que não-vinculados por instrumento específico de Direito Internacional positivo. 
Essa construção de valores compartilhados e de obrigação de zelar pela proteção e pela construção desse sistema institucional e normativo de certa forma já estava anunciado pela CIJ na decisão do Caso Barcelona Traction, de 1970, quando dizia a Corte que além das situações contratualmente estipuladas pelos Estados, há situações em que se colocam valores maiores que têm de ser preservados.

A discussão do Caso Barcelona Traction ganha nova dimensão, quando se vê a construção progressiva de Direito Internacional voltado para a proteção dos direitos fundamentais, e isso vem nortear, inclusive, a evolução em matéria de sucessão de Estados.

Há valor maior a ser preservado, e esse valor maior é a dignidade e a condição do ser humano. Reflexão, no mesmo sentido e na mesma direção, apresentava Friedrich Carl von Savigny, no ensaio "Sobre a vocação do nosso tempo para a codificação e para a Ciência do Direito", de 1814, quando diz: "o direito se confunde com a vida, e o direito será tanto melhor, quanto mais próximo da vida e das necessidades vitais do homem estiver". Savigny já o tinha enxergado e afirmado, em 1814.

São Paulo, junho de 2007.

\section{Referências}

SAVIGNY, Friedrich Carl von. Vom Beruf unserer Zeit für Gesetzgebung und Rechtswissenschaft. Freiburg i.B.: Mohr, 1892.

. De la vocacion de nuestro siglo para la legislacion y la ciencia del derecho. traducción de Adolfo G. Posada. Argentina: Heliasta, 1977. .Vocazione del nostro secolo per la legislazione e la giurisprudenza. Bologna: Forni, 1968. 


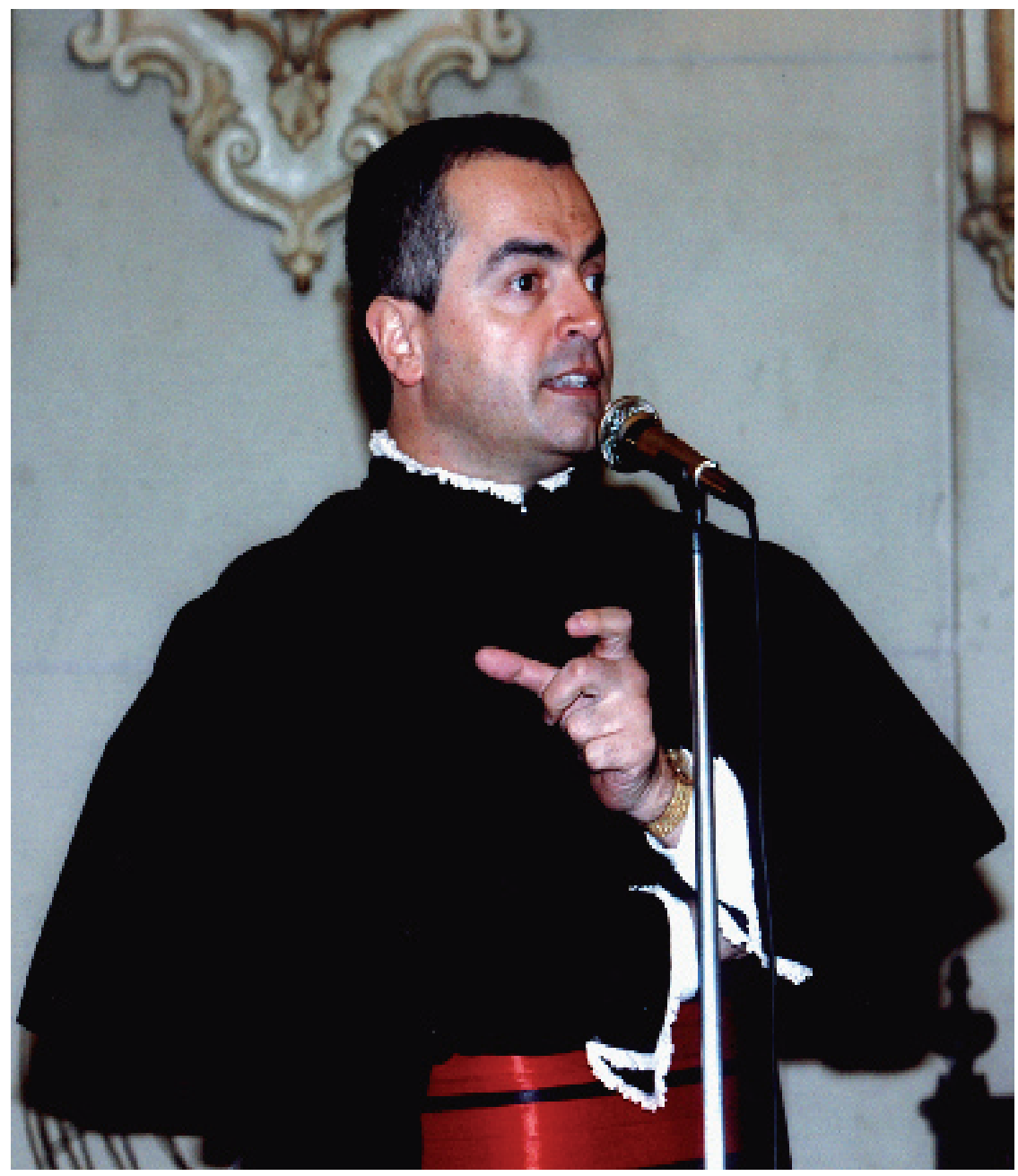

Professor Titular Paulo Borba Casella ${ }^{10}$

${ }_{10}$ Foto: José da Silva Xavier. 